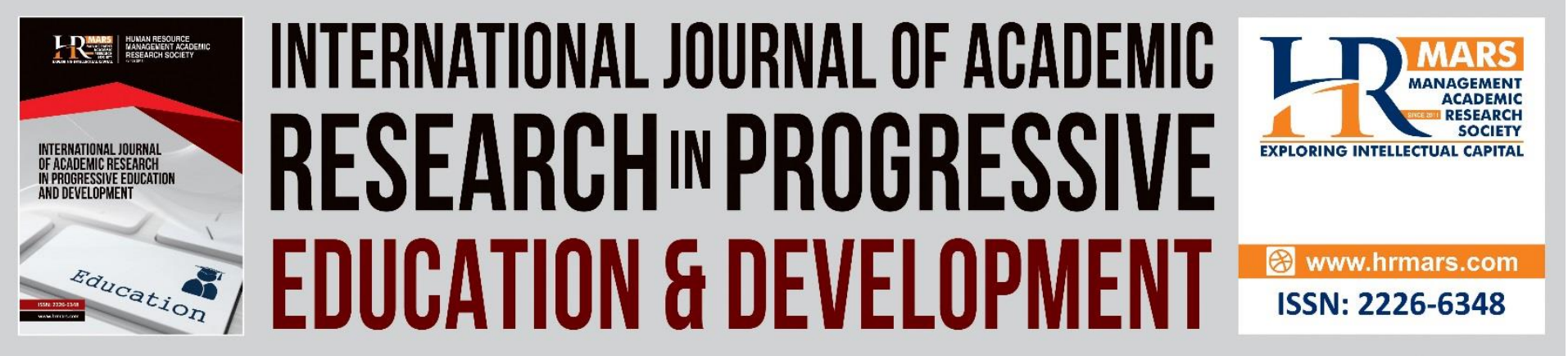

\title{
Excellent Teachers and Their Job Satisfactions: An Analysis at Malaysia's Standpoint
}

Kazi Enamul Hoque, Ahmad Zabidi Abdul Razak, Mosa. Fatema Zohora

To Link this Article: http://dx.doi.org/10.6007/IJARPED/v1-i4/12015

DOI: 10.6007/IJARPED/v1-i4/12015

Received: 19 September 2012, Revised: 25 October 2012, Accepted: 09 October 2012

Published Online: 25 November 2012

In-Text Citation: (Hoque et al., 2012)

To Cite this Article: Hoque, K. E., Razak, A. Z. A., \& Zohora, M. F. (2012). Excellent Teachers and Their Job Satisfactions: An Analysis at Malaysia's Standpoint. International Journal of Academic Research in Progressive Education and Development, 1(4), 240-255.

Copyright: @ 2012 The Author(s)

Published by Human Resource Management Academic Research Society (www.hrmars.com)

This article is published under the Creative Commons Attribution (CC BY 4.0) license. Anyone may reproduce, distribute, translate and create derivative works of this article (for both commercial and non-commercial purposes), subject to full attribution to the original publication and authors. The full terms of this license may be seen at: http://creativecommons.org/licences/by/4.0/legalcode

\section{Vol. 1(4) 2012, Pg. 240 - 255}

Full Terms \& Conditions of access and use can be found at http://hrmars.com/index.php/pages/detail/publication-ethics 


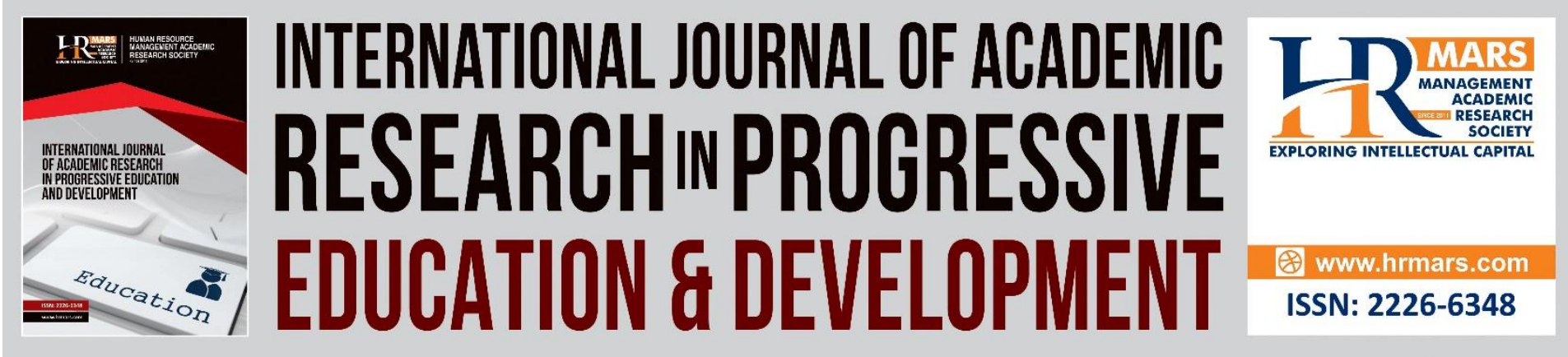

\title{
Excellent Teachers and Their Job Satisfactions: An Analysis at Malaysia's Standpoint
}

\author{
Kazi Enamul Hoque, Ahmad Zabidi Abdul Razak, Mosa. \\ Fatema Zohora \\ Faculty of Education, University of Malaya, Kuala Lumpur, Malaysia \\ Email: keh2009@um.edu.my
}

\begin{abstract}
This study aimed to see the relationship between excellent teachers' thinking and their job satisfaction. Five thinking domains of excellent teachers had been identified by the previous study in Malaysia. This study sought the impacts of these domains on the job satisfaction of the excellent teachers. The Pearson Correlation was used to investigate the relationships between five Excellent Teaching Thinking Model's Components with sixteen factors of Herzberg's Theory of Job Satisfaction. Sample of the study involved 103 excellent teachers of secondary schools of Malaysia. Malaysian excellent teachers have job satisfaction in the three areas of their thinking domain such as management styles, their expectation and teaching objectives. No correlation was established between teacher's job satisfaction and other two thinking domains i.e. excellent teachers' teaching philosophy and pedagogical knowledge. The findings of this study offer valuable information for educational policy makers, educational managers particularly the principals, teachers and excellent teachers.
\end{abstract}

Keywords: Excellent Teacher, Job Satisfaction, Teachers' Thinking Domain

\section{Background}

Excellent Teacher (ET) or Guru Cemerlang Scheme in Malaysia came into effect in 1993 with a view to providing a new career route for experienced and high achieving potential teachers. It is also an alternative to management and leadership posts. The aim of ETs is to retain teachers to use their pedagogic and other skills at school level for the greater betterment of students across the whole school and adjoined schools. Furthermore, EDs should be role model and provide demonstration classes to their colleagues to improve their effectiveness through coaching and mentoring. Under ET scheme, teachers who are non-graduate (DG29), graduate (DG 41) and principals are to be promoted to grade DG 32, DG 44 and DG 52 respectively. Since the beginning of the scheme, about 3595 teachers have been promoted as excellent teachers (NST, 2008). Teachers who have five years experience are eligible to become ETs, and to gain this status they have to undergo an external assessment. The government has the expectation that with their continuous support in terms of professional development, excellent teachers' knowledge, beliefs and instructional practices will make this reform workable (Putnam and Borko, 1997, 2000). 
The scheme is an application based and the qualified teachers should be willing to meet the expectation of an excellent teacher and have their application endorsed by their principal. The ETs need to provide evidence of work that address the identified needs of a particular group or groups of pupils; and successfully pass a procedure of external assessment against national standards developed for this scheme. The scheme is open to any teacher who has five years experience, meets the criteria and has the support of their principals.

After the introduction of the excellent teacher's scheme, Sahandri et al (2008) had the contribution of finding 5 components of excellent teaching thinking model such as Teachers Teaching Philosophy, Pedagogical Content Knowledge, Management Styles, Teachers Expectation and Teaching Objectives. This study aims to explore the satisfaction level of excellent teachers in the areas of above mentioned 5 components of excellent teaching thinking model.

\section{Research Questions}

With a view to achieving the above aim, the following research questions have been formulated:

a) Is there any relationship between teachers' teaching philosophy and their job satisfaction?

b) Are pedagogical content knowledge and job satisfaction related?

c) What is the relationship between management styles and job satisfaction?

d) Do teachers' expectation and job satisfaction go side by side?

e) Is there any relationship between excellent teachers' teaching objectives and job satisfaction?

\section{Literature Review}

Definition of Excellent Teachers and Background of Excellent Teachers Scheme in Malaysia

Excellent teacher can be defined as attributes and skills that make good, effective, likeable teacher and the type of teacher the other regular teachers aspire to become. In a study by Cheah (2007), excellent teacher is defined as having mastery skills of their content areas, develop effective classroom management and discipline skills, and possess consistent and respectable character.

In the Malaysian context, based on the criteria set by the MOE, an Excellent Teacher or as the term usually referred to in Malay Language, which is Guru Cemerlang, refers to an award given to a teacher who is regarded as an expert in his field of teaching and subject matter. The MOE states that the rationale of providing this reward is due to the progression of teacher promotion which in the past, only teachers who fit the criteria will be promoted to the post of top administrators in schools or education officers and in most cases, after getting promoted, the respective teacher seems to be shifting from teaching in the classroom to doing administrative work. According to the MOE, this leads to two implications: teachers who are expert and dedicated in their subject matter are lost in the system and their skills and talents are inaccessible due to the promotions. When the Excellent Teacher Promotion Skill was introduced in 1993, the MOE specifies its specific objectives as follow: 
- To acknowledge teachers who are excellent in their field or subject

- To improve the quality of teaching

- To be role models to other teachers

- To enhance school excellence by utilizing the experience and expertise of the Excellent Teachers

- To expand the horizon of promotion in educational services

- To promote teachers without leaving teaching behind or changing to administrative duties

- To give promoted teachers opportunity to get promoted to a higher grade quickly

\section{Application of Excellent Teacher Post}

In the Malaysian education system, any teacher who is interested in holding the post of an excellent teacher can apply for the post by filling in the required Excellent Teacher Application Forms, depending on their various salary scheme or salary grades such as DG 44 or DGA32. Upon submission of the application through the Principals or Headmasters of the applicant's respective schools, the evaluation and selection procedures begin. These steps are undertaken by the Inspectorate Division of the MOE. At least two Inspectorate Officers from the State Department Office will be involved in assessing the Excellent Teacher Candidate. All applications however are subjected to high Performance Appraisals Marks (at least above $85 \%$ for the past three consecutive years) obtained by the excellent teacher candididate.

\section{Present Scenario of Excellent Teachers' Scheme in Malaysia}

The Excellent Teacher promotion scheme in Malaysia was first introduced in 1993. As part of Malaysia's Ministry of Education (MOE) move towards its recognition of teaching excellence, the Excellent Teacher award was set up. This move was one of the measures of promoting quality in education and the recognition of the key role played by teachers. The move too was consistent with the need to give due recognition to good teachers. The strategy was undertaken with the intention of maintaining excellent teachers in the classroom without having them forgo higher pay and promotion. As a result, some of these excellent teachers may earn salaries higher than that of their principals.

Recently, in conjunction with the celebration of Teacher's Day, at the national level on the 16th of May 2009, the present Malaysian Minister of Education has made several important announcements pertaining to the Excellent Teacher Scheme. They include the following:

- The government has approved an immediate increase of 2,141 Excellent Teacher and Principal posts for graduate education service officers in secondary schools nationwide

- The government has also decided to provide several Excellent Teacher posts for graduate education service officers in primary schools

- The quota of posts for Excellent Teacher would be increased as follow:

a. Special Grade C posts will be increased from 24 to 36 posts

b. Grade DG 54 from 100 to 134 posts

c. Grade DG 52 from 250 to 336 posts

d. Grade DG 48 from 1000 to 1345 posts 
e. Grade DG 44 from 4000 to 5379 posts

(All of the above are for secondary schools)

f. Grade DG 48 for primary schools, 173 posts of Excellent Teacher are created

g. Grade DG 44 for primary schools, 1737 posts of Excellent Teachers are created. (Source: NST news online, 30/10/2009)

The announcement made has certainly proved that the MOE is serious in its effort to upgrade the teaching profession in terms of quality among Malaysian teachers.

In 2006, the Government with the same intention and effort of encouraging more teachers to perform at the excellence level and enjoy the benefit has increased the quota for Excellent Teachers by 300 percent. Until December 2007, a total of 2866 teachers in service have been selected to fill in the Excellent Teacher quota in the various grades. In 2008, 3595 teachers are in the process of undergoing programmes to become Excellent Teachers (New Straits Times, 2008).

\section{Expectations from Excellent Teachers}

Expectations from Excellent Teachers can be based on the characteristics of Excellent Teachers as laid out in the Concept of Excellent Teachers Manual produced by the MOE. The expectations include the following:

a. An outstanding personality which includes practicing, strong ethics in the teaching profession and acting as role models to other teachers

b. An expert in his field and subject matter

c. Possess the ability to produce excellent results/learning outcomes

d. Possess excellent communication skills

e. An individual with high potential as an educator

f. A contributor to the nation's education development

\section{Excellent Teacher Service and Management Stipulations}

After being appointed as an Excellent Teacher, the MOE has stipulated the following status of appointment and posting procedures:

a. The Excellent Teacher will be placed on a special scheme without having to fill in the post of promotion.

b. The Excellent Teacher will be permanently required to teach the subject which he is certified to be an expert.

c. The Excellent Teacher is not allowed to hold any administrative post.

d. The Excellent Teacher can be posted anywhere by the MOE depending on the MOE service needs.

e. The Excellent Teacher who has accepted the post is not allowed to return to his previous teaching post as a regular teacher

f. The Excellent Teacher can be transferred to any schools from time to time depending on the MOE service needs.

The above conditions are listed in Section D of the Guidelines and Reference Terms of the Excellent Teacher Concept Manual produced by the MOE. 


\section{An Overview of Similar Excellent Teacher Scheme (ETS) or Career Path for Teaching Excellence in Various Countries}

\begin{tabular}{|c|c|c|c|}
\hline No. & $\begin{array}{l}\text { Name of } \\
\text { Country }\end{array}$ & Year Started & Brief Background \\
\hline 1. & UK & $\begin{array}{l}\text { Established } \\
\text { in 2004; } \\
\text { came into } \\
\text { effect in } \\
2006\end{array}$ & $\begin{array}{l}\text { A new career route for experienced teachers } \\
\text { and is an alternative to management and } \\
\text { administrative posts. Its aim is to allow teachers } \\
\text { to concentrate on using their pedagogical skills } \\
\text { in ways which will have positive impact, } \\
\text { improving pupil's attainment across the whole } \\
\text { school. }\end{array}$ \\
\hline 2. & Scotland & 2001 & $\begin{array}{l}\text { Known as the Scottish Chartered Teacher } \\
\text { Scheme. Designed to recognize and reward } \\
\text { teachers who attained high standards of } \\
\text { practice. It is aimed to benefit students in two } \\
\text { main ways: by attracting and retaining effective } \\
\text { teachers and by ensuring all teachers continue } \\
\text { to engage in effective modes of professional } \\
\text { learning. }\end{array}$ \\
\hline 3. & $\begin{array}{l}\text { United } \\
\text { States }\end{array}$ & $\begin{array}{l}\text { Created in } \\
2006\end{array}$ & $\begin{array}{l}\text { A federal program which provides funding for } \\
\text { school districts and states to develop and } \\
\text { implement innovative ways to provide financial } \\
\text { incentives for teachers and principals who raise } \\
\text { student achievement and close the gap in some } \\
\text { of America's highest-need schools. }\end{array}$ \\
\hline 4. & $\begin{array}{l}\text { Australia } \\
\text { (New } \\
\text { South } \\
\text { Wales) }\end{array}$ & 2007 & $\begin{array}{l}\text { A system known as the 'performance-based } \\
\text { remuneration system' which is based on } \\
\text { evidence of attaining increasing levels of } \\
\text { knowledge and skills. This system provides a } \\
\text { system for certifying teachers who attain higher } \\
\text { levels of professional standards. }\end{array}$ \\
\hline 5. & Singapore & $\begin{array}{l}\text { December } \\
2007\end{array}$ & $\begin{array}{l}\text { The GROW package is 'Growth of Education } \\
\text { Officers through better Recognition, } \\
\text { Opportunities and seeing to Well-being. The } \\
\text { package gives teachers more recognition for } \\
\text { excellence and commitment to their calling, } \\
\text { more career opportunities and professional } \\
\text { development. }\end{array}$ \\
\hline
\end{tabular}

All of the above literature review of various aspects of Excellent Teacher scheme shows scarce research pertaining to the impact of job satisfaction among Excellent Teachers. However, there is evidence from research which sought to investigate the factors influencing the Excellent Teachers' Thinking Model (Sahandri et al., 2008) and the failure of the Excellent Teacher Scheme (ETS) in England (The Times Online, 3 August 2009). 
Therefore, this article would like to discuss and put forward a research focusing on the selected domains from the Excellent Teachers' Thinking Model and their relationship to job satisfaction. It is also hoped that this research would highlight the factors contributing to teacher's reluctance in applying for the post of Excellent Teachers, specifically among Malaysian teachers.

\section{Definition of Job Satisfaction and its relation to Excellent Teachers}

A positive and healthy school culture translates into increased teacher job satisfaction and productivity. Realizing the impact school culture has on teacher attitudes and morale, Hart, Wearing, and Conn (2000) created an instrument to access organizational factors relating to school culture. Eleven such factors were identified to be assessed: appraisal and recognition, curriculum coordination, effective discipline policy, excessive work demands, goal congruence, participative decision-making, professional growth, professional interaction, role clarity, student orientation, and supportive leadership. Managing an appropriate balance of these factors appears to be key to creating and maintaining a positive environment. According to Perie and Baker (1997), workplace conditions had a positive relationship with a teacher's job satisfaction. Stolp (1994) indicated that school culture correlated directly with teacher attitudes about their work and that stronger cultures had more motivated teachers who experienced higher job satisfaction and increased productivity.

Teacher autonomy has also been shown to impact job satisfaction. Perie and Baker (1997) found that teachers with greater autonomy showed higher levels of job satisfaction than those with less autonomy, and suggested that school districts that are able to increase teachers' control over their classrooms and other school decisions stand to increase the longterm job satisfaction of its staff members. Empowering teachers and including them in the decision-making process can be a productive tool that appears to influence the school culture in a positive way.

Job satisfaction can be described in terms of intrinsic and extrinsic factors. Intrinsic factors are those factors surrounding the job itself and have the greatest impact on job satisfaction. These include such things like a feeling of accomplishment or self worth, personal growth and professional development, and a supportive environment in which to work. Satisfaction often comes as a result of daily activities, or interactions with students, which affirm that learning is taking place.

Research seems to indicate that extrinsic factors surrounding the job including things like salary, fringe benefits, school safety, and level of support by administration, and job security, do not significantly impact the level of job satisfaction of teachers (Baughman, 1996; Perie \& Baker, 1997; Johnson \& Johnson, 1999). Many teachers enter the profession because they enjoy working with children. While extrinsic factors do not strongly impact the level of job satisfaction for teachers, there is a connection. Absence of these factors or a deficiency in the level of these factors is often associated with job dissatisfaction (Johnson \& Johnson, 1999), and no doubt effects attitudes surrounding the work environment. Extrinsic factors ultimately affect staff morale and teacher productivity. 
Job satisfaction is critical to teacher commitment and school effectiveness, and actions by school administrators create distinct environments that are highly predictive of the level of job satisfaction for the teaching staff (Shann, 1998).

\section{Excellent Teachers' Thinking Model and Conceptual Framework}

Excellent teachers have their own styles and thinking that is different from other teachers (Pressley and McCormick, 1995). Excellent teachers, who are resilience, have a sense of efficacy, professional and personal identities. This resilience adds to existing knowledge of variations in teachers' work, lives, and effectiveness and contributes to the debate on standards, quality and retention that has long lasting impact on school effectiveness (Gu \& Day, 2007). When excellent teachers have the intention of retention, it indirectly denotes the job satisfaction. In Malaysia, excellent teacher is an awarded post and they have limited empowerment though education system is very much centralized. From this position of power over the learners, they play a vital role in the process of educational assessment and selection (Leach \& little, 1999) that motivates them positively. On the other hands, Sahandri et al (2008) stated that the thinking domains of excellent teachers are strongly influenced by their background and environmental factors. The conceptualized background factors in their study were teachers' sex, experience, subject specialization and expertise, level of teaching, total teaching hours per week and academic qualification whereas the environmental factors were students background, needs, class size and climate, school objectives and environments, examination systems, parents and community pressure and their traditions. With the consideration of these background and environmental factors, excellent teachers' thinking model has been developed with five domains such as excellent teachers' teaching philosophy, their pedagogical content knowledge, management style, and expectation and teaching objectives. This study has intended to find the influence of these five domains on the different areas of their job satisfaction (Herzberg,1987) such as advance, achievement, work itself, recognition, responsibility, personal growth, status, security, subordinate, personal life, peers, salary, work conditions, supervisor, policy and supervision.

\section{Research Methodology}

This study, titled "Excellent teachers and their job satisfaction" is considered a correlation of sorts as it aims to establish the relationship between the independent predictable variables (Excellent teachers' thinking model) with the dependent variable (job satisfaction).

Gay (2000) argued that correlative research involves collecting data to determine whether, and to what degree, a relationship exists between two or more quantifiable variables. The resulting relationship either predicts or establishes a relationship between variables.

\section{Population and Sampling}

The population of the study consisted of the excellent teachers of the secondary schools of Malaysia. The total number of excellent teachers is 5736 in secondary schools since the project started (MOE, 2008, 2009).

A set of questionnaires for 155 excellent teachers were sent but the responses from a total of 115 teachers were returned from different schools. All together the responses of 12 teachers excluded from subsequent analysis due to a failure to properly complete the questionnaires. The response rate was $74.19 \%$ for teachers. Overall, the responses of 103 
teachers $(66.45 \%)$ were used for the purpose of this study with the aggregated mean of teachers' responses.

With regards to sampling, Gay (2000) says, "for correlation, causal-comparative, and experimental research, some experts consider the magic 'general guideline' to be 30 . Thus for correlation studies at least 30 subjects are needed to establish the existence or nonexistence of a relationship." With this in mind, the responses 103 excellent teachers) were justifiably sufficient to represent the population being studied.

\section{Instruments: Their Validity and Reliability}

Questionnaires on Excellent Teaching Thinking Model's Components (Teachers Teaching Philosophy, Pedagogical Content Knowledge, Management Styles, Teachers Expectation and Teaching Objectives) with sixteen factors of Herzberg's Theory of Job Satisfaction (advance, achievement, work itself, recognition, responsibility, personal growth, status, security, subordinate, personal life, peers, salary, work conditions, supervisor, policy and supervision) were used to collect the quantitative data for this study. The sources of these questionnaires were adapted from the questionnaires of Sahandri et al. (2008) for excellent teachers' thinking model and Herzberg for their Job Satisfaction. The validity of the content had been determined through expert opinions who were specialists in the content area selected for this study. The preliminary versions of both questionnaires were tested in a pilot study on a random sample of 30 excellent teachers. The result from this pilot study confirmed that the items in both questionnaires were relevant, although some minor alternations were required.

To verify the convergence validity of the instrument used for this study, multi item scales were analyzed based on factor analysis. The scales include 5-Excellent Teaching Thinking Model Components (Teachers Teaching Philosophy, Pedagogical Content Knowledge, Management Styles, Teachers Expectation and Teaching Objectives) with one criterion variable sixteen items of Herzberg's Theory of Job Satisfaction (advance, achievement, work itself, recognition, responsibility, personal growth, status, security, subordinate, personal life, peers, salary, work conditions, supervisor, policy and supervision). At the beginning of the underlying assumptions were observed before proceeding to the subsequent phases of factor analysis.

Confirmatory factors and reliability analysis were also performed to determine the dimensionality for 5-Excellent Teaching Thinking Model Components and sixteen factors of Herzberg's Theory of Job Satisfaction. The results of factor analysis for independent variables were determined to be five factors, with factor loading ranging from .615 to .917, using principal component analysis and Varimax rotation procedures amounting for $65.72 \%$ of total variance. In case of measuring job satisfaction, the direct Oblimin rotation method was used due to the failure of the Varimax rotation method to get a clean factor. Factor analysis on sixteen items about job satisfaction produced a one-dimensional factor with the factor loading ranging from .59 to .76 . This factor cumulatively obtained $76.70 \%$ of the variance in the data, with explanatory power as expressed by the eigenvalue 11.29. The factor loadings were acceptable. In other words, these 16 items were internally consistent, all measuring the same basic construct. 
A reliability test of the measures were performed, of which the Chronbach alphas were all above the lower limit of acceptability (Chronbach alpha >.60) (Nunnally, 1978). Hence all the measures were highly reliable.

\section{Findings}

In this study, Pearson Correlation was used to investigate the relationships between five Excellent Teaching Thinking Model's Components (Teachers Teaching Philosophy, Pedagogical Content Knowledge, Management Styles, Teachers Expectation and Teaching Objectives) with sixteen factors of Herzberg's Theory of Job Satisfaction (advance, achievement, work itself, recognition, responsibility, personal growth, status, security, subordinate, personal life, peers, salary, work conditions, supervisor, policy and supervision).

Looking into Table 1, the result of Pearson Correlation shows that, there is a significant correlation between "Management Styles and Job Satisfaction" ( $r=$.039), "Teaching Expectation and Job Satisfaction" $(r=.020)$ and "Teaching Objective with Job Satisfaction" ( $r=$ .007). The Table also shows that, there is no significant correlation between Teachers' Teaching Philosophy and Job Satisfaction" ( $r=.058)$ and "Pedagogical Content with Job Satisfaction" ( $r=.062)$. 
Table 1: Person Correlations of the Excellent Teachers' Thinking Model with Job Satisfaction

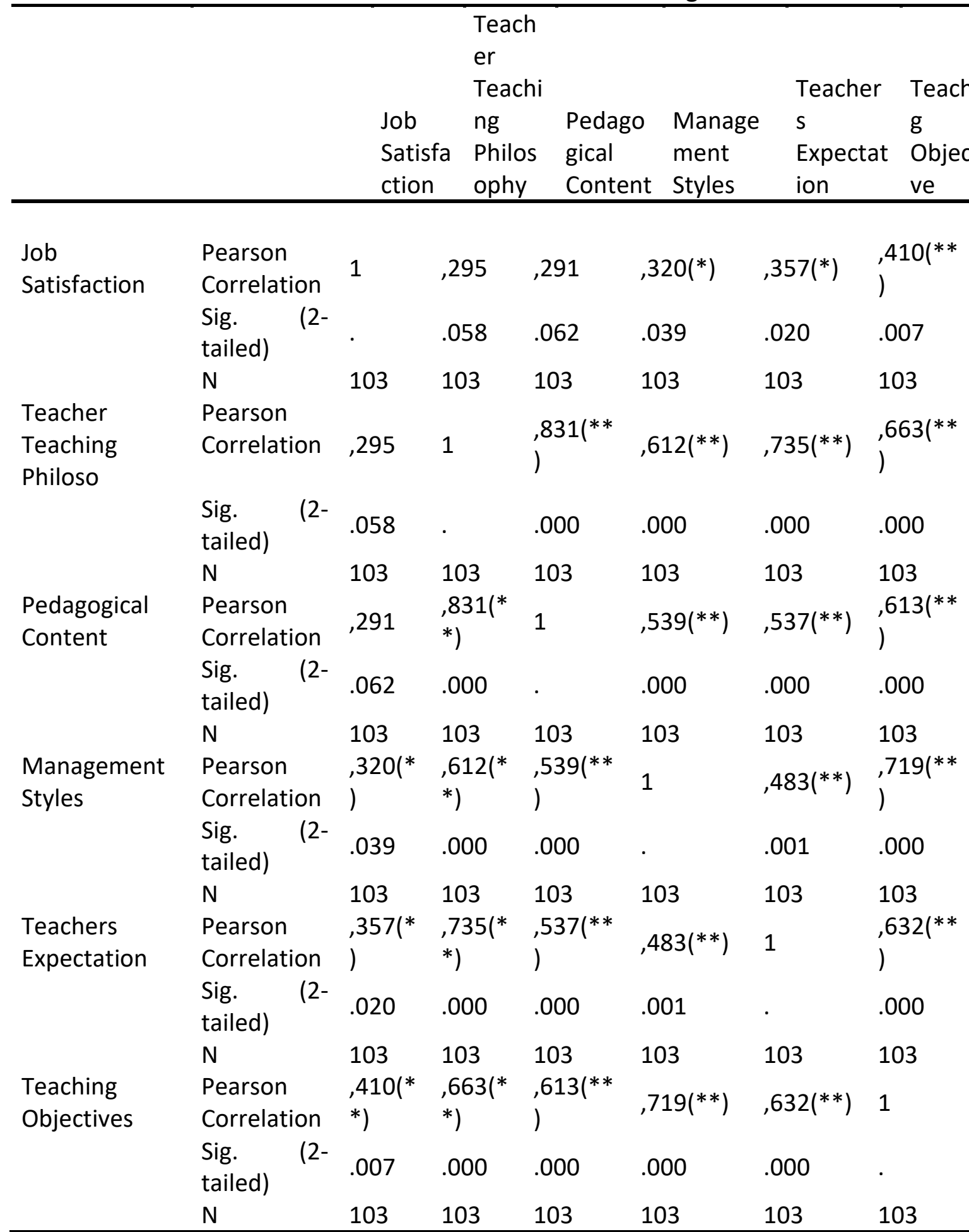

Notices: ${ }^{*}$ Correlation is significant at the 0.05 level (2-tailed). ${ }^{* *}$ Correlation is significant at the 0.01 level (2-tailed).

\section{Interpretation}

The relationship between Teaching Thinking Model in terms of management styles, teaching expectations and teaching objectives show high level of satisfaction of the excellent teachers with the school management styles, teacher's expectation and teaching objectives. 
Furthermore, there is no significant correlation between teachers teaching philosophy and pedagogical content with job satisfaction. These insignificant correlations indicate that, the excellent teachers were not satisfied with the teachers teaching philosophy and pedagogical content

\section{Discussion}

\section{Excellent Teachers Teaching Philosophy and Job Satisfaction}

Despite the dominance of instrumental, psychological approaches to educational theory and practice in Malaysia, a different understanding of the value and dynamics of education is often articulated informally in cultural representations and in personal recollections. This alternative understanding is one in which the personal characteristics of a teacher and the relation between student and teacher are often paramount. This study presents a broadly existential and explicitly relational way of understanding education, or, rather, pedagogy. From this understanding, excellent teachers follow their own philosophy "teacher himself is the best method'. In this study there is found no significant relationship between teachers' teaching philosophy and their job satisfaction. It is possible, as with the advancement of new technology, situation changes overnight. What was most effective yesterday, could be less effective tomorrow. As uncertainty exists, frustration prevails. Therefore, excellent teachers change their teaching system frequently and keep busy to innovate new technique for next day. In that case, there is no way of satisfaction rather tension (Higgins, 2010).

\section{Pedagogical Content Knowledge and Job Satisfaction}

Excellent teachers should have excellent knowledge (Mohd Sahandri, Hapidah \& Mohammad Reza, 2008) in their subject matter. But nobody is satisfied with his knowledge as there is no limit of knowing. The more one will explore the more he will know. There is found no significant relationship between teachers' knowledge and their satisfaction in this study. It is because excellent teachers are very much aware of the fact that knowledge thirst is unmeatable. The findings of Goldschmidt and Phelps (2010); Nilsson (2009) show that teachers' content knowledge has had significant impact on student performance. But no study has been found to examine the relationship between teachers' content knowledge and job satisfaction.

\section{Management Styles and Job Satisfaction}

Management cooperation helps excellent teachers to show their excellence in their day to day activities. If management non-cooperation exists in any school, excellent teachers feel uncomfortable that decreases their productivity (Alam \& Hoque, 2010). This study shows that excellent teachers find school management very cooperative and supportive. They have expressed their utmost satisfaction with the management styles of school principals. It is because excellent teacher ship is awarded by the government with the recommendation of principals. As principals are familiar and involved with the process, they are keen enough to provide the necessary support for the excellent teachers. Chen, Beck and Amos (2006) have identified different leadership styles that have significant relationship with employee's job satisfaction.

Lobban, Hasted and Farewell (1998) also have found the positive relationship between management styles and job satisfaction. 


\section{Teachers' Expectation and Job Satisfaction}

Teachers' expectation can be increased with the increase of environmental factors, which are the skills to deal with various students needs. Teachers' expectation also can be increased if the number of teaching periods per week is decreased at optimum level. Reducing teachers teaching hours per week bring satisfaction for them as they feel relax. Moreover, they can concentrate in their professional development activities that help them to cope with the present global trend. Excellent teachers become satisfied if he has the scope to increase his skill as his optimum level (Alam et al., 2010). He is happy by departing epoch-oriented knowledge to his students (Hoque et al., 2010). In this study, it is found that excellent teachers in Malaysia are getting most of their expected facilities and so they are satisfied with their job.

This finding is in the line with Chang and Chang (2010), Sag (2008) and Auwarter and Aruquete (2008) where they had the observation of high satisfaction level of teachers and students after fulfilling their desired expectation.

\section{Excellent Teachers' Teaching Objectives and Job Satisfaction}

Excellent teachers have their own plan to set up most effective ways to test the learning activities of their students. Thus, they examine the learning outcomes of their effort and justify the level of their teaching capacity. In this study, excellent teachers are found highly satisfied with fulfilling their teaching objectives. As excellent teachers are empowered slightly more than other teachers, the study result is not unexpected. Cotic (2010) and Demirel (2010) also had found the positive significant relationship between students-teachers' objectives and their satisfaction when desired objectives are achieved.

\section{Suggestions and Conclusion}

As a conclusion, the excellent teachers thinking model has an impact on excellent teaching job satisfaction especially the management styles, teachers' expectations and teaching objectives. Besides, the school management or principal leadership styles of these particular schools had maintained the satisfaction of the excellent teachers and it seemed that the teachers have been motivated by the management styles.

In addition, teachers' expectations in this study are high because the more satisfied and motivated the excellent teachers are, the higher the expectation they will have. This shows a good relationship of high level of job satisfaction with high expectation. However, the relationship of teaching objectives with job satisfaction indicates that, the excellent teachers are satisfied with the teaching objectives which are about producing excellent teaching and students' outcomes. Thus, this may indicate that the excellent teachers like to see good performance of their students and their good results.

In contrast, the excellent teachers were satisfied with their teacher teaching philosophy, perhaps it is against their personal philosophy of becoming excellent teachers. It could be that teacher teaching philosophy itself is very hard for the excellent teachers to follow and achieve. Thus, teacher teaching philosophy is against their wish or not well philosophized according to their views. Pedagogical content seemed to cause dissatisfaction among the excellent teachers whereby the excellent teachers might totally disliked by them perhaps going against what is written in the content for instruction or teaching. 
Therefore, the school management or policy makers should look into those aspects because if there is any disagreement of dissatisfaction in the excellent teachers thinking model, it could lead to other dissatisfaction of the other components of the excellent teacher thinking model components. This could de-motivate excellent teachers in carrying out their works or could lead to the excellent teachers to relinquish their post as excellent teachers and have the intention of going back to their previous post as regular teachers. In addition, this could de-motivate the rest of the teachers applying for the excellent teachers post. In light of this, the management or government should consider those factors and try to provide a good environment for excellent teachers in order to attract others to apply for this post.

It is also suggested for further research pertaining to excellent teachers to be conducted by taking into consideration the conditions stipulated by the Ministry of Education. These conditions are the terms that come together upon the acceptance of the post of 'Excellent Teachers' by the excellent teachers. Informal interviews and discussion conducted among excellent teachers and also regular teachers who are qualified to apply for the post, reveal the fact that many of them were dissatisfied with some of the terms given such as 'The excellent teacher who has accepted the post is not allowed to return to his previous teaching post as a regular teacher' and 'the excellent teacher can be transfered to any schools from time to time depending on the MOE service needs'. Therefore, these factors of dissatisfaction could be looked into in future research as being the factors contributing to the reluctance of many qualified teachers to apply for the post of excellent teachers in Malaysia.

\section{References}

Alam, G. M., \& Hoque, K. E. (2010) Who gains from "Brain and Body Drain" Business Developing/developed world or individuals: A comparative study between skilled and semi/unskilled emigrants, African Journal of Business Management 4(4), 534-548

Alam, G. M., Hoque, K. E., Rout, G. K., \& Priyadarshani, N. (2010) Who does gain from EFA State Business of Education or Private Higher Education Business in Developing Nation: A study to understand the policy impact in Bangladesh? African Journal of Business Management 4(5)

Auwarter A. E., \& Aruguete, M. S. (2008) Effects of student gender and socioeconomic status on teacher perceptions. Journal of Educational Research, 101 (1), 243-246.

Catherine Cheah Ming Ming. (2007). First Year Students' Perceptions of Excellent Teachers. Unpublished Project Report. Faculty of Education, University of Technology, Malaysia.

Chang, C. Y., \& Chang, Y. H. (2010) College science students' perception gaps in preferredactual learning environment in a reformed introductory earth science course in Taiwan. Journal of Geography in Higher Education 34(2), 187-203.

Chen, H. C., Beck S. L., \& Amos L. K. (2005) Leadership styles and nursing faculty job satisfaction in Taiwan. Journal of Nursing Scholarship, 37(4), 374-380.

Demirel, M. (2010) An Evaluation of Elementary and Secondary Schools' Class Guidance Curriculum. Egitim Ve Bilim-Education and Science. 35(156), 45-60.

Gay, L. R. (2000). Educational Research; Competencies for Analysis and Application (6th ed.). USA: Prentice-Hall Inc.

Goldschmidt, P., \& Phelps, G. (2010) Does teacher professional development affect content and pedagogical knowledge: How much and for how long? Economics of Education Review, 29(3), 432-439 
Gu, Q., \& Day, C. (2007) Teachers resilience: A necessary condition for effectiveness. Teaching and Teacher Education, 23(8), 1302-1316.

Hart, P., Wearing, A. J., \& Conn, M. (2000). Development of the school organizational health questionnaire: A measure for assessing teacher morale and organizational climate. The British Journal of Educational Psychology [Online], 70(2), 218-228.

Herzberg, F. (!987) One more time: how do you motivate employees? Harvard Business Review, 65(5), 109-120

Higgins, C. (2010). Human Conditions for Teaching: The Place of Pedagogy in Arendt's Vita Activa. Teachers College Record, 112(2), 407-445.

Lawrence, I., Elizabeth, K., \& Jenny, W. (2007). Research on Performance Pay For Teachers. Australian Council for Educational Research.

Chen, H. C., Beck S. L., \& Amos L. K. (2005) Leadership styles and nursing faculty job satisfaction in Taiwan. Journal of Nursing Scholarship, 37(4), 374-380.

Demirel, M. (2010) An Evaluation of Elementary and Secondary Schools' Class Guidance Curriculum. Egitim Ve Bilim-Education and Science. 35(156), 45-60.

Gay, L. R. (2000). Educational Research; Competencies for Analysis and Application (6th ed.). USA: Prentice-Hall Inc.

Leach, E. F., \& Little, A. W. (eds) (1999) Education, cultures and econmics: dilemmas for development. New Work: Routledge Falmer

Lobban, R. K., Husted, J., \& Farewell, V. T. (1998). A comparison of the effect of job demand, decision latitude, role and supervisory style on self-reported job satisfaction. Work and Stress, 12(4), 337-350.

Ministry of Education, Malaysia. (2009). Retrived on 15 May from http://www.moe.gov.my/tayang.php?/laman=guru_cemerlang\&unit=guru=en

Ministry of Education, Malaysia. (2004). 'The Development of Education' National Report of Malaysia.

Ministry of Education, Singapore. (2009). What is the GROW 2.0 Package? Retrieved on 15 May from http://moe.gov.sg/GROW

Sahandri, M. G. H., Hapidah M., \& Reza M. G. (2008). Excellent Teachers' Thinking Model : Implications for Effective Teaching. Australian Journal of Teacher Education. 33 (4): 1127.

New Straits Times Online. (2009). Raising more top calibre teachers with Better intakes. Retrieved from http://www.nst.com.my/current_news/NST/

National Institute for Teaching Excellence. (2009). The system for teacher and student advancement- teacher incentive fund (TIF). Retrieved on 5 December, 2009 from U.S. Department of Education's Web Site.

Nilsson, P. (2009) From lesson plan to new comprehension: exploring student teachers' pedagogical reasoning in learning about teaching. European Journal of Teacher Education, 32(3), 239-258.

Nunnaly, J. C. (1978). Psychological Theory (2nd ed.). New York: McGraw-Hill.

Perie, M., \& Baker, D. P. (1997). Job satisfaction among America's teachers: effects of workplace conditions, background characteristics, and teacher compensation. National Center for Education Statistics. Item Number 97-471

Putnam, R., \& Borko, H. (1997). Teacher learning:Implications of new views of cognition. In B.J. Biddle, T.L. Good, \& I.F. Goodson (Eds.), The international handbook of teachers and teaching (pp. 1223-1296). Dordrecht, The Netherlands:Kluwer. 
Putnam, R., \& Borko, H. (2000). What do new views of knowledge and thinking have to say about research on teaching? Educational Researcher, 29(1), 4-15.

Sag, R. (2008) The expectations of student teachers about cooperating teachers, supervisors, and practice schools. Egitim Arastirmalari Eurasian Journal of Educational Research, $8(32), 117-132$.

Stolp, S. (1994). Leadership for school culture. ERIC digest, 91. Retrieved September 9, 2009 from ERIC database on the World Wide Web: http://eric.uoregon.edu/publications/digests/digest091.html

Times Online. (2009). Government Scheme to Boost Teachers' Careers Is a Failure. Retrieved from http://www.timesonline.co.uk/tol/education 